DOI:

\title{
FORMS OF PRESENTATION OF COMIC CATEGORY
}

\author{
Leila Diasamidze \\ PhD \\ Batumi Shota Rustaveli State University \\ (Batumi, Georgia) \\ e-mail: eila.diasamidze82@mail.ru
}

\begin{abstract}
The article deals with the historical origin of a joke, its definition and differentiation of humor variations, social functions, forms of comic on the basis of British and American jokes.

A joke in its contemporary sense exists only a century. Before that a joke meant an unimportant but a characteristic event in the life of a historic personality. Nowadays a joke exists in contemporary folklore of big cities. It is a kind of resonance to all parts of life.

A joke as a genre and a form of comic can fulfill the following functions: communicative, compensatory and cognitive. Joke themes vary but the quantity of latent messages they convey is stable - only sixteen. Messages give us opportunity to define the society 's humor specification which is reflected in short humor folklore texts.
\end{abstract}

Keywords: forms of comic; humor; British and American jokes; contemporary folklore

\section{ФОРМЫ ВОПЛОЩЕНИЯ КОМИЧЕСКОГО}

\author{
Лейла Яковлевна Диасамидзе \\ PhD, ассистент профессора, \\ Батумский государственный университет \\ имени Шота Руставели \\ (Батуми, Грузия) \\ e-mail: leila.diasamidze82@mail.ru
}

\begin{abstract}
Аннотация. В статье даётся определение и характеристика различных проявлений и социальных функций комического, виды социальной функции юмора, перечисляются его литературные и фольклорные формы существования. Выявляется, что на современном этапе наиболее востребованной и употребительной в фольклоре является короткая юмористическая история, или анекдот, по широте охвата социальных функций превосходящая все остальные формы проявления категории комического. Рассматривается история его происхождения и приводится современное определение его в литературоведении. На примере британского и американского анекдотов выявлена специфика и тематика коротких юмористических текстов.
\end{abstract}

Ключевые слюва: формы комического; юмор; британские и американские анекдоты; фольклор.

ВВЕДЕНИЕ И ОБЗОР ЛИТЕРАТУРЫ. Термин «анекдот» (от греч. anékdotos«неизданный») впервые возник в Византии с появлением в 550 г. сатирической книги историка Прокопия Кесарийского под названием «Тайная история», дословно, 
«Неопубликованное». Книга была посвящена хронике скандалов и примечательных историй при императорском дворе. Однако задолго до Прокопия Кесарийского из уст в уста передавались истории с неожиданным остроумным финалом. Каждой эпохе свойственна своя форма анекдота и свое чувство юмора. В западной Европе анекдоты получили распространение благодаря популярности шуточных и развлекательных рассказов в духе «Декамерона» Боккаччо. Малые повествовательные жанры шуточного характера именовались в западно - европейской литературе фаблио и фацеции. Эпоха Возрождения уже имела своих собирателей анекдотов, и самым знаменитым собирателем того времени является итальянец Браччолини, составивший свой сборник «фацеций»; первое его издание датируется 1470 годом. Наиболее известными из его последователей были Корнециани, Рабле, Фришлин, Генрих Бебель и другие. В современном же литературоведении анекдотами считаются небольшие устные/письменные шуточные рассказы самого различного содержания с неожиданной остроумной концовкой.

Анекдот распространен в современном городском фольклоре и рождается как народный отклик на события жизни, охватывая все ее стороны, от быта до большой политики. Анекдоты относятся к особому виду устного народного творчества их, особое отличие состоит в образности, краткости, остроте, а также актуальности в лишь определенный временной отрезок. За его пределами он перестает восприниматься как собственно анекдот, нуждаясь в соответствующем предисловии с комментариями (БСЭ.1975; Dmitriev 2003). Отметим, что изначально в этимологии «Фацеций», как тогда чаще назывались анекдоты, содержится их качественная характеристика и заложенное в них исконно дружелюбное начало. В латыни facētiae означало, собственно, юмор, шутки и остроты. Слово происходит от прилагательного facētus, что означает в первом значении «дружелюбный, приветливый», затем - «тонкий, изысканный, изящный» и лишь затем, в четвертом и пятом значениях - тонкий, остроумный и наконец, - «забавный». Требовалось употребить специальное прилагательное aspěre/acerbae (колкий, едкий), чтобы шутка превратилась в одностороннее злое веселье - глумление, едкие насмешки и колкости. Проведенный этимологический экскурс настаивает на дружелюбном характере устного народного творчества и подчеркивает изначально здоровую основу его посыла, который состоит не в том, чтобы уколоть и уязвить, а дружелюбно повеселиться над забавным. В основе колкостей, глумления и насмешек, как правило, лежит личное недружелюбное отношение и они имеют такое же отношение к юмору, как частный случай к общему правилу. В этом плане появление так называемого черного юмора наводит на мысль об уровне душевного здоровья человеческой общности. Вплоть до XIX века анекдоты были очень распространены в своем первоначальном значении, то есть в виде короткого рассказа о незначительном, но характерном происшествии из жизни исторического лица.

Теоретик и критик кинокомедии Р.Н. Юренев приводит в своей работе 37 оттенков смеха, в зависимости от характера эмоций, сопутствующих юмору и не все они носят откровенно дружелюбный характер: «Смех может быть радостный и грустный, добрый и гневный, умный и глупый, гордый и задушевный, снисходительный и заискивающий презрительный и испуганный, оскорбительный и ободряющий, наглый и робкий, дружественный, простосердечный, саркастический и наивный, грубый, многозначительный и беспричинный, торжествующий и оправдательный, бесстыдный и смущенный. Можно еще увеличить этот перечень: веселый и печальный, нервный, истерический, издевательский, 
физиологический, животный и даже умный смех» (Юренев 1980, 35). Любопытно отметить тот факт, что из приведенного списка лишь 15, то есть менее половины видов и оттенков смеха носят явно положительный характер. Это говорит о многогранном характере смеха как средства воздействия на личность, с помощью которого можно поднять настроение и довести до агрессии и слез лишь невербальным проявлением, - мимикой и жестом. В то же время юмор, в отличие от смеха с его почти 40 оттенками, всегда доброжелателен по сути.

При разграничении понятии смешного и комического следует подчеркнуть, что комическое является в первую очередь понятием социальным, имеющим отношение к человеческому обществу. Этимологически комическое означает «смешное» от греч. kōmikós «веселый, смешной». Эта категория универсальная, так как все на свете можно рассматривать «комически». Известный американский психолог Гордон Олпорт, президент Американской психологической ассоциации, обладатель Золотой медали Американского психологического фонда, считал, что жизнь зрелого человека не может быть привязана только к потребностям и обязанностям. Человек должен получать удовольствие от жизни и в этом важную роль играет самообъективация, - его отношение к себе и внешнему миру. Одним из основных компонентов подобной самообъективации является юмор. Он помогает находить радостное и хорошее в обычных ситуация, что благотворно сказывается на отношениях с людьми (Allport 2002, 51-59).

А.Х. Маслоу, - один из немногих психологов, серьезно исследовавших позитивные измерения человеческого опыта. Выдающийся американский психолог включил обладание чувством юмора в перечень харак-теристик высокоразвитой самоактуализирующейся личности. Один из пунктов характеристики обычного человека, у которого ничто не отнято, гласит: философское, невраждебное чувство юмора (Маслоу, Maslow 2008). И этот момент особенно хотелось бы подчеркнуть: от седой старины и до наших дней природно и этимологически юмор связан с добротой и доброжелательностью, являясь по истокам фольклорным жанром, идущим из глубины народной души.

В ходе культурного развития выделились ирония и юмор как разновидности амбивалентного смеха. Притча о юморе гласит, что радость и горе встретились ночью в лесу и, не узнав друг друга, вступили в брачный союз, от которого и родился юмор.

РЕЗУЛЬТАТЫ И ДИСКУССИЯ. Понятия иронии и юмора для нас особенно важны, так как они в разной мере представлены в предмете нашего исследования - коротких фольклорных юмористических текстах, и нам предстоит определить удельный вес этих видов комического, ведь ни в чем так не обнаруживается характер людей, как в том, что они находят смешным. Эта истина в одинаковой мере применима как по отношению к отдельным индивидам, так и к нациям и общенациональному характеру.

Юмор имеет различные литературные формы - анекдот или шутка, монолог и диалог, рассказ, остроумный ответ собеседнику и т.п. Называют также переходные разновидности юмора иронического, остроумного, сатирического, забавного, а также эксцентрического. Рассмотрим вкратце особенности каждого них и области их применения.

Иронией называется форма речи, в которой истинный смысл скрыт или противоречит используемым словам. Ирония создает ощущение, что предмет обсуждения не таков, каким он кажется. По определению Аристотеля, ирония есть «высказывание, содержащее насмешку над тем, кто так действительно думает». Более жесткой, бескомпромиссной формой иронии 


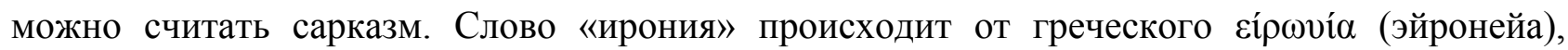
означающего «притворство».

Существуют различные формы иронии:

1. Прямая ирония - способ принизить, придать отрицательный или смешной характер описываемому явлению.

2. Антиирония противоположна прямой иронии и позволяет представить обьект антииронии недооцененным.

3. Самоирония - ирония, направленная на собственную персону.

4. Ироническое мировоззрение - состояние души, позволяющее не принимать на веру и стереотипы и не относиться слишком серьезно к различным общепризнанным ценностям (Bergson 1992, 166).

Существует расхожее мнение, что эта черта в наибольшей мере свойственна англичанам. И не без основания, ведь само слово «юмор» одним из первых было употреблено в Англии Б. Джонсоном в его сатирических комедиях, к примеру, «Всяк со своей причудой». В век Просвещения в Англии юмор нашел отражение в так называемых «семейных романах» Филдинга, Голдсмита, Смолетт, а вершина юмора 18 века - проза С. Стерна. Его традиции в 19 в. продолжил величайший мастер юмора Ч. Диккенс. Комическое и его составная - юмор, носят отпечатки менталитета жителей страны изучаемого языка. Ни в чем другом так не проявляется характер народа, как в том, над чем он смеется и какими способами он создает эффект комического.

Как известно, в основе комического лежит фактор неожиданности и несоответствия ожиданиям. Создатель теории когнитивного диссонанса современный американский ученый Л. Фестингер приписал противоречивым знаниям об окружающем мире мотивационный статус, за счет которого чувство дискомфорта может быть достигнуто с помощью когнитивных методов. Применяя когнитивный диссонанс, можно «достучаться» до человека и повлиять на сделанный им выбор. Элементы когнитивного диссонанса содержатся в юморе, фольклорных текстах, которые содержат ситуации, описывающие дисгармонию мыслей, чувств и поведения человека. Интеллектуальный конфликт между новой информацией и уже имеющимися мнениями, установками и представлениями, названный когнитивным диссонансом, побуждает произвести переоценку интеллектуальных и этических ценностей (Festinger 2004, 367-370).

Следует различать как социальную функцию комического, так и его формы, имеющие различные ипостаси. Его цель заключается в том, чтобы содействовать изменению поведения личности не под влиянием грубого нажима или необоснованной похвалы, - эти методы одинаково неэффективны, как показало исследование психологов. Юмор, выступающий изначально как способ установления контакта и передачи информации, может служить обоюдоострым оружием самокритики и критики, быть средством нападения и изобличения, а также служить щитом, средством психологической защиты от моральной агрессии или террора, а также способом сокрытия собственного негативного состояния или отношения. Каждой такой социальной функции соответствует своя форма воздействия, что демонстрирует составленная нами таблица: 
Таблица 01

\begin{tabular}{|c|l|l|}
\hline № & \multicolumn{1}{|c|}{ Социальная функция юмора } & \multicolumn{1}{|c|}{ Формы подачи юмора } \\
\hline 1 & $\begin{array}{l}\text { Компенсаторная: доставление радости, положительных } \\
\text { эмоций }\end{array}$ & анекдот, шутка \\
\hline 2 & Средство установления контакта и передачи информации & $\begin{array}{l}\text { юмореска, фельетон, } \\
\text { шутка, анекдоты }\end{array}$ \\
\hline 3 & Воспитательное средство & $\begin{array}{l}\text { притчи, пословицы и } \\
\text { поговорки }\end{array}$ \\
\hline 4 & Средство психологической защиты & анекдот, каламбур \\
\hline 5 & Демонстрация негативного отношения & $\begin{array}{l}\text { ирония, сарказм, сатира, } \\
\text { насмешка }\end{array}$ \\
\hline 6 & Эвристическая, разрушающая стереотипы & анекдот \\
\hline
\end{tabular}

Независимо от условий жизни и политической атмосферы, юмор в своих различных проявлениях присутствует в жизни любого индивида и любой нации и особенно в условиях демократического общества, характерной чертой которого является свобода слова. В связи с этим политический юмор утратил былую популярность и на первый план выходят универсалии повседневности, семейных связей, отношений полов и т.д. Список существующей тематики включает около пятидесяти наименований. Приведем лишь некоторые из них: 1. Водители, дороги. 2. Регулярная армия. 3. Школа и родители. 4.Гостиницы и сфера обслуживания. 5.Дети и их родители. 6.Мужчины и женщины. 7.Животные и их хозяева. 8. Компьютеры и компьютерщики. 9. Врачи и медицина. 10.Полиция, таможня, налоговая служба. 11. Мультфильмы и их герои. 12. Наркоманы и алкоголики. 13. Лица другой национальности. 14. Рестораны, пивные. 15 Продавцы и покупатели. 16. Психические больные и медики. 17. Мобильные и смартфоны. 18. Работа и «работнички». 19. Семья и ее обитатели. 20. Реклама и те, кто ее смотрит. 21. Религия и те, кто верит. 22. Охота, рыбалка, охотники и рыболовы. 23. Эротика. 24. Романтика и романтик. 25. Начальники и секретарши. 26. Сказки и сказочники. 27. Спорт и спортсмены. 28. Теща и другие родственники. 29. Самолеты, пароходы, поезда и путешествия. 30. Тюрьма, суд, уголовники и адвокаты. 31. Политика, политики. 32. Искусство и искусствоведы. 34. Ковбойский юмор. 35. Черный юмор. 36. Прикольные, странные и непонятные. 37. Новогодние. 38. Юриспруденция. 39. Юмор в коротких штанишках. 40. Вредные привычки. 41. Телефонные разговоры. 42. Пациенты и врачи. 43. Цирковой юмор. 44. Уголовный юмор. 45. Студенческие. 46. Объявления. 47. Иностранный юмор. 48. Разное.

Упомянем установленный нами разброс тематики текстов по проблемам, более всего волнующим английское и американское общества: I. Мужчины и женщины. II. Семья. III. Вредные привычки. IV. Финансовые проблемы. V. Черный юмор. VI. Политика, страна. Новыми для последних лет являются темы экологии, НЛО, безработицы, рекламы и телепередач. Менее значимы темы, касающиеся транспорта и питания. Юмор стал широко привлекаться в коммерческих целях в рекламе, буклетах, рекламных роликах, передачах TV юмористической направленности в качестве средства воздействия на потенциального покупателя и зрителя, играя роль мягко, но эффективно действующего 25-го кадра. Ореол запрета снят с многих социальных тем, и юмор через положительные эмоции участвует в 
регуляции человеческих отношений, как бы передавая функции укора и осуждения другим проявлениям комического - иронии, сатире и сарказму.

Эмоции, как известно, образуют основную мотивационную систему человека и определяют его поведение. Однако отношения юмора и смеха не сводимы к простому тождеству: сила смеха не находится в прямой пропорции с качеством юмора. Бывает достаточно элементов юмора, чтобы вызвать лавину смеха в большой аудитории в силу физиологической заразительности смеха. Известно, что смех приводится в действие усилием двенадцати мимических мышц, в то время, как при отрицательных эмоциях их задействовано вдвое больше. Неудержимый смех, громкий хохот еще не показатель высокого уровня юмора, так как чувство юмора и смешливость - не совсем одно и то же. Тем не менее, комизм всегда отождествляется с чем-то смешным. Английский юмор, как правило, не вызывает смеха до слез, и внешне он чаще проявляется улыбкой или усмешкой. Видимо, не случайно в словарной статье английского фразеологического словаря напротив слова humour стоит лишь один оборот: a dry humour - «манера острить, говорить смешные вещи с невозмутимым видом». Он проиллюстрирован характерным примером, взятым у С.Моэма: «He was a wag and he enjoyed his own dry humour» (Kunin 1984, статья Humour). Характерно также то, что нам встретился единственный фразеологизм со словом England - Merrie/Merry England, т.е. буквально «веселая Англия». Обе словарные статьи красноречиво указывают на эмоциональную особенность проявления юмора у англичан. Анекдоты широко циркулируют в англофонной среде. При этом юмор островной Англии и юмор континентальных США, отраженный в анекдоте, имеет свою специфику. Если первому присуща сдержанность и требование к соблюдению речевого этикета, порой в неадекватной ситуации, то для американского юмора более существенны другие стороны действительности, подлежащие обсуждению. Иронизировать по-английски, - «точно, скрыто или лукаво высмеивать, вышучивать, но при этом вполне положительно, одобрительно относиться к тому, о ком идет речь», - находим мы у Н.И. Кондакова (Kondakov 1976, 232). Сами термины «иронизировать» и «ирония» несколько расходятся в своей оценке предмета насмешки. От иронии недалеко до сарказма, в то время как иронизировать можно и добродушно.

Назовем, наконец, эвристическую роль юмора, побуждающего к гибкости мышления разрушением стереотипов. В юморе осознается и отражается игра случайностей и бесконечная вариативность развития. Каждая юмористическая короткая история имеет свой скрытый серьезный подтекст, некое послание, число таких посылов - мессиджей, вполне исчислимо и поддается классификации. В результате проведенного нами ранее исследования 1000 британских и американских анекдотов, выявлена специфика британского и американского юмора с качественной и количественной сторон. Она характеризует своего рода болевые точки каждого общества, - латентные пожелания об изменении ситуации по каждому из посылов (Diasamidze 2005, 98-92; 2017). В результате построенная нами модель британского и американского юмора, включающая традиционные посылы, позволила получить представление о специфике английского и американского юмора, отраженного в коротких фольклорных юмористических текстах.

ЗАКЛЮЧЕНИЕ. Таким образом, формы воплощения комического характеризуются разнообразием в зависимости от выполняемой ими социальной функции: компенсаторной, состоящей в доставлении положительных эмоций, коммуникативной, дидактической, 
защитной и эвристической. На современном этапе наиболее востребованной и употребительной в фольклоре является короткая юмористическая история, или анекдот, по широте охвата социальных функций превосходящая все остальные формы проявления категории комического.

\section{LIST OF REFERENCES}

Allport G.W. (2002). Personality formation: Selected works /Stanovleniye lichnosti: Izbrannyye Trudy / [Per. s angl. L. V. Trubitsynoy i D. A. Leontyeva]; pod obshch. red. D. A. Leontyeva. Moskva: Smysl.

Bergson H. (1992). Le rire. Moskva: Iskusstvo.

Bolshaya entsiklopediya/. (1975). [ Big encyclopedia]. Moskva: Izdatelstvo Entsiklopediya, -t.2, statya «anekdot».

Diasamidze L.Y. (2005). Osnovnyye kharakteristiki angliyskogo anekdota kak tipa messidzhey. [Main characteristics of English joke as a type of message]. Intellect, N 1 (21) S.89-92;

Diasamidze L.Y. (2017). Teksttipologicheskaya interpretatsiya zhanra «anekdot». [Text typological interpretation of joke genre]. Saarbrucken: LAP LAMBERT Academic Publishing RU. 200 P.

Dmitriyev D.V. (2003). Tolkovy slovar russkogo yazyka.[Explanatory dictionary of the Russian language]. Moskva: Izdatelstvo AST, statya «anekdot».

Festinger L. (2004). A theory of cognitive dissonance. Stanford: Stanford University Press.

Kunin A.V. (1984). Anglo - russkiy frazeologicheskiy slovar. [English-Russian phraseological dictionary]. Moskva: Izdatelstvo Russkiy yazyk.

Kondakov N.I. (1976). Logicheskiy slovar - spravochnik. [Logical dictionary - reference book]. Moskva: Nauka.

Luk A.N. (1968). O chuvstve yumora i ostroumii. [About a sense of humor and wit]. Moskva: Iskusstvo.

Maslow A.H. (2008). Motivation and personality. New York: Harper and Brothers.

Yurenev R. N. (1980). O komedii. [On the comedy]. Moskva: Iskusstvo.

\section{For citation:}

Diasamidze, L. (2020) FORMS OF PRESENTATION OF COMIC CATEGORY. International Scientific-Pedagogical Organization of Philologists “WEST-EAST" (ISPOP). Scientific Journal WEST-EAST. Vol 3 N1 (March, 2020). pp. 11-16. doi:

\section{Для цитирования:}

Диасамидзе, Л. Я. (2020) ФОРМЫ ВОПЛОЩЕНИЯ КОМИЧЕСКОГО

// International Scientific-Pedagogical Organization of Philologists "WEST-EAST " (ISPOP).

Scientific Journal WEST-EAST. Vol 3 N1 (March, 2020). C. 11-16. doi:

Information about the author: Leila Diasamidze $\mathrm{PhD}$, Assistant Professor, Batumi Shota

Rustaveli State University, Batumi,Georgia.

Research interests: linguistics, comparative literary studies, linguoculturology.

e-mail: eila.diasamidze82@mail.ru 
Сведения об авторе: Лейла Яковлевна Диасамидзе - доктор филолгии, преподаватель английского языка в государственном университете им. Ш. Руставели, Батуми, Грузия. Область научных интересов, - лингвистика, сравнительное литературоведение, лингвокультурология.

e-mail: eila.diasamidze82@mail.ru

Manuscript received: 12/15/2019

Accepted for publication: $01 / 16 / 2020$

Рукопись получена: 12/015/2019

Принята к печати: 01/16/2020 